\title{
Arterial stiffness should be evaluated with other inflammatory markers in patients with subclinical hypothyroidism
}

\author{
A rigidez arterial deveria ser avaliada com outros marcadores \\ inflamatórios em pacientes com hipotireoidismo subclínico
}

1 Department of Cardiology, Gulhane Medical Academy Ankara, Turkey 2 Department of Internal Medicine, Gulhane Medical Academy Ankara, Turkey

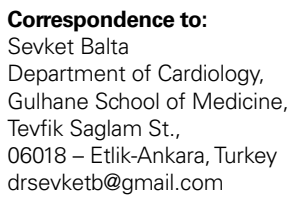

Received on May/13/2013 Accepted on June/6/2013
Sait Demirkol', Sevket Balta', Mustafa Dinc², Seyit Ahmet Ay², Ugur Kucuk', Murat Unlu'

$\mathrm{W}$ e read the article "Assessment of the elasticity properties of the ascending aorta in patients with subclinical hypothyroidism by tissue Doppler imaging" by Mustafa Yurtdas and cols. with great interest (1). The authors aimed to investigate whether aortic elastic properties were affected in subclinical hypothyroidism $(\mathrm{SCH})$ using tissue Doppler imaging (TDI). They concluded that $\mathrm{SCH}$ is associated with impaired elasticity of the ascending aorta. Elastic properties of the ascending aorta can be directly evaluated by the reproducible measurement of the upper wall movements of the ascending aorta by TDI in SCH patients. We are grateful to the authors for their contribution in a successfully designed and documented study.

Cardiovascular diseases are the most important causes of mortality and morbidity in developed countries worldwide. SCH is associated as independent of classical risk factors for atherosclerosis (2). SCH is also related to an increased risk of CAD events and CAD mortality in patients with high thyroid stimulating hormone levels $(\geq 10$ $\mathrm{mIU} / \mathrm{L})(3)$. Arterial stiffness represents the viscoelastic properties of the vessel wall, indicates vascular damage, and is a measure of the degree of atherosclerosis (4). It has received increased attention due to its role as an independent prognostic factor for hypertension, chronic kidney disease, diabetes, and heart failure. Increased arterial stiffness is a common indicator of atherosclerotic involvement of the vascular structure, indicating $\mathrm{CAD}$, cerebrovascular disease, and peripheral arterial disease. It can also be affected by the atherosclerotic risk factors, such as smoking, alcohol consumption, hypercholesterolemia, older age and autoimmune disease (5). In addition, some inflammatory disease, including systemic lupus erythematosus, psoriasis vulgaris, and Behcet disease may be related to arterial stiffness parameters (6). As for this point of view, in the Yurtdas and cols. study, the authors did not mention some of the affecting factors. It would be better if they gave information about these factors.

Furthermore, some medications, such as antihypertensive treatment, including angiotensin-converting enzyme inhibitors, angiotensin receptor blocker, statins, medications used for weight loss, and medical history of drug addiction may influence arterial stiffness parameters. It would be useful and results might be different, if the authors described these factors.

Finally, arterial stiffness is a non-invasive method to assess endothelial dysfunction in clinical practice, and it can be affected by many factors (7). Arterial stiffness itself without other inflammatory markers may not provide information to clinicians about atherosclerosis of SCH patients (8). Thus, we think that it should 
be evaluated together with other serum inflammatory markers. We believe that these findings will enlighten further studies about arterial stiffness on subclinical hypothyroidism.

\section{REFERENCES}

1. Yurttas M, Gen R, OzcanT, Aydın MK. Assessment of the elasticity properties of the ascending aorta in patients with subclinical hypothyroidism by tissue Doppler imaging. Arq Bras Endocrinol Metab. 2013;57(2):132-8.

2. Valentina VN, Marijan B, Chedo D, Branka K. Subclinical hypothyroidism and risk to carotid atherosclerosis. Arq Bras Endocrinol Metab. 2011;55(7):475-80.

3. Rodondi N, Den Elzen WPJ, Bauer DC, Cappola AR, Razvi S, Walsh $\mathrm{JP}$, et al. Subclinical hypothyroidism and the risk of coronary heart disease and mortality. JAMA. 2010;304(12):1365-74.
4. Altun B, Bulucu F, Demirbas S, Karaman M, Ay SA, Cakar M, et al. The relationship between some of the cardiovascular risk factors and arterial stiffness parameters in essentially hypertensive patients. Clin Exp Hipertens. 2013;35(6):444-8.

5. Viggiano DPPO, Da Silva NA, Montandon ACOES, Barbosa V de $S$. [Prevalence of thyroid autoimmune disease in patients with systemic lupus erythematosus]. Arq Bras Endocrinol Metab. 2008;52(3):531-6.

6. Balta I, Balta S, Demirkol S, Celik T, Ekiz O, Cakar M, et al. Aortic arterial stiffness is a moderate predictor of cardiovascular disease in patients with Psoriasis vulgaris. Angiology. 2014;65(1):74-8.

7. Balta S, Cakar M, Demirkol S, Unlu M, Kucuk U, Arslan Z. Arterial stiffness itself without other inflammatory markers may not provide information to clinicians. J Clin Hypertens (Greenwich). 2013;15(4):303.

8. Balta S, Demırkol S, Kucuk U, Arslan Z, Unlu M,Yesil FG. Epicardial adipose tissue should be evaluated with other inflammatory markers in patients with subclinical hypothyroidism. Med Princ Pract. 2013;22:603-4. 